\title{
PERTUMBUHAN BAYI BERDASARKAN FREKUENSI DAN DURASI MENYUSU
}

\author{
Juhrotun Nisa $^{1}$ Umriaty $^{2}$, Meyliya Qudriani ${ }^{3}$ \\ Email: nisa.jn20@gmail.com \\ Prodi DIII Kebidanan Politeknik Harapan Bersama \\ Jalan Mataram No. 9 Pesurungan Lor Kota Tegal
}

\begin{abstract}
Abstrak
Bayi ASI eksklusif berpeluang mengalami pertumbuhan normal 1,62 kali lebih besar dibandingkan bayi ASI non eksklusif, tetapi berat badan bayi dapat menurun yang penyebabnya adalah frekuensi pemberian ASI dan jumlah ASI yang diperoleh, termasuk energi dan zat gizi lainnya yang terkandung didalam ASI. Tujuan penelitian ini untuk mengetahui hubungan frekuensi menyusu dan durasi menyusu dengan pertumbuhan bayi. Penelitian ini adalah penelitian survey analitik dengan rancangan cross sectional, dimana populasinya adalah bayi usia 0 s/d 6 bulan yang menjalani ASI Ekslusi. Teknik pengambilan sample dengan accidental sampling dan teknik analisa dengan chi square. Hasil penelitian menujukan bahwa $90.9 \%$ frekuensi menyusu bayi lebih dari 8 kali perhari, dengan durasi menyusu lebih dari 15 menit setiap kali menyusu sebanyak $87.9 \%$ dan berat badan bayi berada di pita kuning sebanyak 6.1\%. Tidak terdapat hubungan antara frekuensi menyusu dan durasi menyusu dengan pertumbuhan bayi.
\end{abstract}

Kata kunci: Frekuensi Menyusu, Durasi Menyusu, Pertumbuhan Bayi.

\begin{abstract}
Exclusive breastfeeding babies have the opportunity to experience normal growth 1.62 times greater than non-exclusively breastfed babies, but the baby's weight can decrease one of the causes is influenced by the frequency of breastfeeding and the amount of breast milk obtained, including energy and other nutrients contained in breast milk. The purpose of this study was to determine the relationship between the frequency of breastfeeding and the duration of breastfeeding with the baby's growth. This study was an analytic survey study with cross sectional design, the population was infants aged 0 to 6 months exclusive breastfeeding. Sampling technique with accidental sampling and analysis technique with chi square. The results showed that 90.9\% of the babies breastfeeding frequency was more than 8 times per day, with a duration more than, than 15 minutes each time as much as $87.9 \%$ and the baby's body weight was in the yellow band as much as $6.1 \%$. There is no relationship between the frequency of breastfeeding and the duration of breastfeeding toward the baby's growth
\end{abstract}

Keywords: Frequency of breastfeeding, duration of breastfeeding, baby growth

\section{PENDAHULUAN}

ASI merupakan makanan yang tepat untuk bayi terutama pada bulan-bulan pertama, karena mengandung zat gizi yang diperlukan bayi untuk membangun dan menyediakan energi (Soetjiningsih. 2008). 
Bayi yang berumur $0-6$ bulan sesuai rekomendasi World Health Organization (WHO) pada tahun 2001 hanya memerlukan ASI saja tanpa cairan atau makanan padat apapun yang disebut dengan ASI eksklusif. Penegasan pemberian ASI eksklusif juga diatur dalam PP Nomor 33 tahun 2012 Pasal 6 yang berbunyi "Setiap ibu yang melahirkan harus memberikan ASI eksklusif kepada bayi yang dilahirkannya"( Lissauer T, 2009).

Pada tahun 2016 cakupan ASI di dunia hanya $36 \%$, sedangkan cakupan ASI di Indonesia pada tahun 2018 sebesar 37.7\% menurun dibandingkan tahun 2017 yaitu $61.33 \%$. Cakupan tersebut masih jauh dari target Indonesia 80\%. Selain itu situasi gizi balita di dunia saat ini sebanyak 155 juta balita pendek (stunting), 52 juta kurus (wasting) dan 41 juta balita gemuk (overweight), sedangkan di Indonesia $17.7 \%$ balita mengalami gizi buruk dan kurang, $30.8 \%$ balita sangat pendek dan $10,2 \%$ sangat kurus dan kurus, dan $8 \%$ balita gemuk (Kemenkes RI, 2018).

Pemberian ASI ekslusif memiliki hubungan yang erat dengan status gizi bayi. ASI sendiri dianggap sebagai satu-satunya makanan yang dibutuhkan bayi dalam 6 bulan pertama kehidupan (Giri M, 2013).

Penelitian yang dilakukan oleh fitri, et al (2014) menyebutkan bahwa bayi ASI eksklusif berpeluang mengalami pertumbuhan normal 1.62 kali lebih besar dibandingkan bayi ASI non eksklusif (nilai $\mathrm{OR}=1.62$ ) dan perkembangan sesuai umur 5.474 kali lebih besar dibandingkan bayi ASI non eksklusif, sedangkan menurut Maryunani (2012) berat badan bayi dapat menurun salah satu penyebabnya dipengaruhi oleh faktor frekuensi pemberian ASI dan jumlah ASI yang diperoleh, termasuk energi dan zat gizi lainnya yang terkandung didalam ASI.

Berdasarkan latar belakang diatas maka penelitian ini dilakukan dengan tujuan untuk mengetahui hubungan frekuensi menyusu dan durasi menyusu dengan pertumbuhan bayi.Kartu Menuju Sehat (KMS) merupakan catatan grafik perkembangan anak yang diukur berdasarkan umur, berat badan dan jenis kelamin. Adapun warna pada grafik terdiri dari bawah garis merah yang artinya kurang gizi baik sedang maupun berat, warna kuning artinya kurang gizi ringan, hijau muda (diatas garis kuning) artinya berat badan cukup atau status gizi baik/normal dan diatas hijau tua artinya berat badan lebih diatas normal (Herliafifah, 2020).

\section{METODE PENELITIAN}

Penelitian ini adalah penelitian survey analitik dengan rancangan cross sectional. Dilakukan di wilayah kerja Puskesmas Kota Tegal dimana populasinya adalah bayi usia 0 s/d 6 bulan yang menjalani ASI Ekslusif. Pengumpulan data dilakukan pada bulan Juni s/d Juli 2020 dengan teknik pengambilan sampel menggunakan accidental sampling. Data yang digunakan adalah data primer, diperoleh melalui pengisian kuesioner. Teknik analisa yang digunakan analisa bivariat menggunakan chi square. Adapun jumlah sampel dalam penelitian ini yaitu 33 ibu yang sedang memberikan ASI Ekslusif.

\section{HASIL DAN PEMBAHASAN}

\section{Hasil}

Tabel 1. Distribusi Frekuensi

Responden berdasarkan

Frekuensi Menyusu, Durasi

Menyusu dan Kurva

Pertumbuhan.

\begin{tabular}{|c|c|c|c|}
\hline No & Variabel & $\mathrm{F}$ & $\%$ \\
\hline \multirow[t]{4}{*}{1.} & Frekuensi & & \\
\hline & Menyusu & & \\
\hline & - $\quad<8 \mathrm{kali} / \mathrm{hari}$ & 3 & $9.1 \%$ \\
\hline & - $\geq 8 \mathrm{kali} / \mathrm{hari}$ & 30 & $90.9 \%$ \\
\hline \multirow[t]{3}{*}{2.} & Durasi Menyusu & & \\
\hline & - $<15$ menit & 4 & $12.1 \%$ \\
\hline & - $\geq 15$ menit & 29 & $87.9 \%$ \\
\hline \multirow[t]{5}{*}{3.} & Kurva & & \\
\hline & Pertumbuhan & & \\
\hline & - Pita Kuning & 2 & $6.1 \%$ \\
\hline & Muda & 12 & $36.4 \%$ \\
\hline & - Pita Hijau Tua & 19 & $57.6 \%$ \\
\hline
\end{tabular}

Berdasarkan tabel 1 dapat diketahui bahwa frekuensi menyusu responden sebagian besar sudah lebih dari $8 \mathrm{kali} / \mathrm{hari}$ yaitu 
90.9\% dengan durasi menyusu $87.9 \%$ lebih dari 15 menit setiap kali menyusu. Adapun kurva pertumbuhan berdasarkan berat badan bayi pada kartu menuju sehat sebagian besar berada pada pita warna hijau tua yaitu 57.6\%.Grafik warna hijau maupun hijau tua pada dasarnya memberikan gambaran bahwa berat badan bayi berada pada grade normal, akan tetapi perlu diperhatikan juga titik grafik sebelumnya. Jika grafik naik artinya berat badan naik, grafik sejajar artinya berat badan sama dengan bulan lalu dan grafik menurun artinya berat badan anak turun. Selain itu, kenaikan berat badan minimal juga menjadi catatan dalam penentuan kenaikan berat badan pada bayi (Herliafifah, 2020).

Tabel 2. Hubungan Frekuensi Menyusu dengan Kurva Pertumbuhan Bayi

\begin{tabular}{|c|c|c|c|c|c|c|c|c|c|c|}
\hline \multirow[t]{2}{*}{ No } & \multirow{2}{*}{$\begin{array}{l}\text { Frekuensi } \\
\text { Menyusu }\end{array}$} & \multicolumn{2}{|c|}{$\begin{array}{c}\text { Pita } \\
\text { Kuning }\end{array}$} & \multicolumn{2}{|c|}{$\begin{array}{c}\text { Pita Hijau } \\
\text { Muda }\end{array}$} & \multicolumn{2}{|c|}{$\begin{array}{c}\text { Pita Hijau } \\
\text { Tua }\end{array}$} & \multicolumn{2}{|c|}{$\sum$} & \multirow{2}{*}{$\begin{array}{c}\text { P- } \\
\text { Value }\end{array}$} \\
\hline & & $\mathbf{F}$ & $\%$ & $\mathbf{F}$ & $\%$ & $\mathbf{F}$ & $\%$ & $\mathbf{F}$ & $\%$ & \\
\hline 1. & $<8 \mathrm{jam} / \mathrm{hari}$ & 0 & 0 & 2 & $66.7 \%$ & 1 & $33.3 \%$ & 3 & $100 \%$ & \multirow{2}{*}{0.5} \\
\hline 2. & $\geq 8 \mathrm{jam} / \mathrm{hari}$ & 2 & $6.7 \%$ & 10 & $33.3 \%$ & 18 & $60 \%$ & 30 & $100 \%$ & \\
\hline
\end{tabular}

Berdasarkan tabel 2 dapat diketahui bahwa pada responden dengan frekuensi menyusu lebih dari 8 jam perhari $6.7 \%$ berat badannya berada pada pita warna kuning dan sebagian besar berada pada pita warna hijau sebesar $60 \%$, sedangkan pada bayi yang menyusunya kurang dari $8 \mathrm{kali} / \mathrm{hari}$ sebagian besar berat badannya berada pada pita warna hijau muda yaitu $66.7 \%$. Adapun uji hubungan didapatkan nilai $\mathrm{p}$ value $>0.05(0.5>0.05)$ yang artinya tidak terdapat hubungan antara frekuensi menyusu dengan pertumbuhan bayi 0-6 bulan yang masih menjalani ASI Ekslusif.

Tabel 3. Hubungan Durasi Menyusu dengan Kurva Pertumbuhan Bayi

\begin{tabular}{|c|c|c|c|c|c|c|c|c|c|c|}
\hline \multirow[t]{2}{*}{ No } & \multirow{2}{*}{$\begin{array}{c}\text { Durasi } \\
\text { Menyusu }\end{array}$} & \multicolumn{2}{|c|}{ Pita Kuning } & \multicolumn{2}{|c|}{$\begin{array}{c}\text { Pita Hijau } \\
\text { Muda }\end{array}$} & \multicolumn{2}{|c|}{$\begin{array}{c}\text { Pita Hijau } \\
\text { Tua }\end{array}$} & \multicolumn{2}{|c|}{$\sum$} & \multirow{2}{*}{$\begin{array}{c}\text { P- } \\
\text { Value }\end{array}$} \\
\hline & & $\mathbf{F}$ & $\%$ & $\mathbf{F}$ & $\%$ & $\mathbf{F}$ & $\%$ & $\mathbf{F}$ & $\%$ & \\
\hline 1. & $<15$ menit & 0 & 0 & 2 & $50 \%$ & 2 & $50 \%$ & 4 & $100 \%$ & \\
\hline 2. & $\geq 15$ menit & 2 & $6.1 \%$ & 10 & $36.4 \%$ & 17 & $57.6 \%$ & 29 & $100 \%$ & \\
\hline
\end{tabular}

Berdasarkan tabel 3 dapat diketahui bahwa pada bayi dengan durasi menyusu kurang dari 15 menit setiap kali menyusu memiliki kemungkinan yang sama pada kurva berat badannya yaitu $50 \%$ pada pita hijau muda dan $50 \%$ pada pita hijau tua, sedangkan pada bayi yang menyusu dengan durasi lebih dari sama dengan 15 menit setiap kali menyusu $6.1 \%$ memiliki berat badan pada pita warna kuning dan $57.6 \%$ berada pada pita warna hijau tua kurva pertumbuhan bayi menurut kartu menuju sehat.

\section{Pembahasan}

Pemberian air susu ibu (ASI) dianjurkan kapan saja setiap kali bayi menginginkannya, sebagai seorang ibu tidak perlu merasa takut jika memberikan ASI dalam jumlah terlalu banyak, karena pada dasarnya ASI mudah diserap dan frekuensi menyusu akan semakin berkurang seiring dengan bertambahnya usia bayi. Kebutuhan ASI cenderung lebih banyak pada saat bayi berusia 2 sampai 6 minggu, bayi akan menyusu dengan frekuensi sekitar 8 sampai 12 kali dalam satu hari, frekuensi menyusu tersebut akan berkurang saat bayi mulai berusia 3 sampai 6 bulan (Hardianti M, 2013).

Hasil penelitian menujukan bahwa 90.9\% responden menyusu lebih dari 8 kali dalam satu hari, hasil penelitian ini bertentangan dengan penelitian yang dilakukan oleh ramadhani (2015) yang menujukan hasil bahwa pada responden penelitiannya justru 71.9\% kurang dari 8-12 kali/hari. Hasil penelitian Sari et al (2017) sejalan dengan penelitian ini yang menujukan hasil bahwa $67.4 \%$ respondennya memiliki frekuensi menyusu yang baik.

Durasi menyusu pada bayi pada dasarnya berbeda, tetapi menurut Arief 
(2009) waktu menyusu yang baik yaitu lebih dari 15 menit. Lama waktu menyusu berdampak pada produksi ASI, dimana ketika bayi menyusu dengan durasi yang sesuai maka bayi akan memperoleh semua kandungan ASI baik dari foremilk maupun hindmilk. Jika bayi mendapatkan semua manfaat ASI maka bayi dapat tumbuh dan berkembang secara optimal (Susanti M, 2012).

Hasil penelitian berdasarkan kurva pertumbuhan Kartu Menuju Sehat (KMS) menujukan bahwa $57.6 \%$ berat badan bayi berada pada pita warna hijau tua dan $6.1 \%$ pada pita warna kuning. Jika grafik berada di daerah dua pita warna kuning (diatas garis merah) menujukan anak tersebut mengalami kurang gizi ringan, jika berat badan berada di dua pita warna hijau muda dan dua warna hijau tua diatas pita kuning menujukan berat badan cukup atau status gizi baik/normal sedangkan empat pita diatas pita warna hijau tua artinya berat badan diatas normal (Sabrina, 2020).

Setelah dilakukan uji statistik menggunakan chisquare tidak terdapat hubungan antara frekuensi menyusu dengan pertumbuhan bayi.Hasil penelitian ini bertentangan dengan penelitian yang dilakukan oleh Erlinawati et al (2019) dengan nilai $\mathrm{p}$ 0.001. Menurut Soetjiningsih (2008) bila bayi sering menyusu setiap 2-3 jam atau 8-12 kali dalam sehari bayi akan cukup mendapatkan ASI dan dapat meningkatkan berat badan dengan rata-rata 500 gram/bulan.

Selain frekuensi menyusu, teknik menyusu yang benar juga berpengaruh terhadap berhasil atau tidaknya menyusui. Jika teknik menyusui ibu sudah benar, maka ibu tidak akan memiliki masalah dalam menyusui, sehingga pemberian ASI dapat optimal dan bayi dapat memperoleh semua manfaat ASI yang ditunjukan dengan kenaikan berat badan yang sesuai dengan kenaikan berat badan minimal sesuai Kartu Menuju Sehat (KMS) (Sari, Tamtomo dan Anantayu, 2017).

Hasil penelitian juga menujukan bahwa tidak terdapat hubungan antara durasi menyusu dengan pertumbuhan bayi, penelitian ini sejalan dengan penelitian Rini et al (2015) dengan nilai $\mathrm{p}=0.209$. Durasi menyusu pada bayi berbeda, ada quick- feeder dan slow feeder. Pada bayi quick feeder bayi biasanya mampu mengosongkan payudara dalam waktu 5 menit dan pada slow feeder sekitar 20 menit atau lebih, dimana diselingi istirahat pendek saat bayi menyusu. Bayi juga tidak dianjurkan menyusu selama berjam-jam dikarenakan takut hanya sekedar nempel pada puting ibu saja, sehingga tidak mendapat manfaat ASI (Adriani dan Wirjatmadi, 2012)

Berdasarkan pernyataan tersebut, perlekatan bayi juga berhubungan dengan durasi menyusu pada bayi. Teknik perlekatan yang baik mencakup sebagian besar areola dan dapat menstimulasi syaraf puting untuk mengirimkan pesan ke otak. Otak akan memerintahkan hipotalamus anterior untuk memproduksi hormon prolaktin dan oksitosin akan dikeluarkan hipotalamus posterior.

Adapun hormon prolaktin berfungsi untuk memproduksi ASI dan oksitosin untuk mendorong ASI keluar agar siap dihisap. Semakin sering ibu menyusu, maka semakin banyak ASI yang diproduksi, sehingga berat badan bayi normal karena mendapatkan semua manfaat dari ASI, sedangkan jika perlekatan bayi salah maka frekuensi dan durasi menyusu tidak akan berpengaruh banyak pada kenaikan berat badan bayi, karena bayi tidak mendapatkan semua manfaat ASI (Reeder, Martin \& Griffin (2011) dalam Rahayu et al, 2018).

\section{KESIMPULAN DAN SARAN}

Berdasarkan hasil penelitian tersebut maka dapat disimpulkan bahwa 90.9\% frekuensi menyusu bayi lebih dari 8 kali perhari, dengan durasi menyusu lebih dari 15 menit setiap kali menyusu sebanyak $87.9 \%$ dan berat badan bayi berada di pita kuning sebanyak $6.1 \%$. Tidak terdapat hubungan antara frekuensi menyusu dan durasi menyusu dengan pertumbuhan bayi.

Pemberian ASI Ekslusif pada bayi perlu di evaluasi/dipantau teknik perlekatan dan teknik menyusuinya, karena pada bayi yang cukup mendapatkan ASI berat badannya akan meningkat sesuai dengan kenaikan berat badan minimal pada Kartu Menuju Sehat (KMS). 


\section{REFERENSI}

Adriani M dan Wirjatmadi B. 2012. Peranan Gizi dalam Siklus Kehidupan. Jakarta:Kencana.

Arief, N. 2009. Panduan Ibu cerdas ASI dan Tumbuh Kembang Bayi. Yogyakarta: Media pressindo.

Erlinawati, Amir dan Puteri. 2019. Hubungan Frekuensi Pemberian Asi Pada Ibu Menyusui Dengan Peningkatan Berat Badan Bayi. Jurnal Doppler Universitas Pahlawan Tuanku Tambusai. Volume 3(2): 9-18.

Fitri, Chundrayetti, dan semiarti (2014). Hubungan Pemberian ASI dengan Tumbuh Kembang Bayi Umur 6 Bulan di Puskesmas Nanggalo. Jurnal Kesehatan Andalas. Volume 3 (2).

Hardianti M. 2013. Seberapa Seringkah Frekuensi dan Durasi Menyusui itu Seharusnya. http://www.vemale.com

Herliafifah, Riska. 2020. Kartu Menuju Sehat (KMS), Ketahui Cara Membaca dan Manfaatnya. Diupload tanggal 17 September 2020. https://hellosehat.com/parenting/anak1-sampai-5-tahun/cara-membaca-kms/\#gref

Giri, M. (2013). Hubungan Pemberian Asi Eksklusif Dengan Status Gizi Balita Usia 6-24 Bulan Di Kampung Kajanan, Buleleng. JST (Jurnal Sains dan Teknologi). Volume 2(1).

Kemenkes RI. 2018. Laporan Nasional RISKESDAS 2018. Jakarta: Kemekes RI.

Lissauer T, Fanaroff A. 2009. At a glance neonatologi. Jakarta: Erlangga Medical Series;

Maryunani.(2012). Analisis Faktor yang Memengaruhi Produksi ASI pada Ibu Menyusui Bayi Usia 4-6 Bulan (Primipara)
Studi di Wilayah Kerja Puskesmas Rubaru Kabupaten Sumenep

Rahayu, Novayelinda dan Agrina. 2018. Hubungan Teknik Perlekataan Menyusui dengan Kejadian Regurgitasi Pada Bayi Usia 0-2 Bulan. JOM FKp. Volume 5 No 2.

Reeder, Martin \& Griffin. 2011. Maternity nursing: Family, newborn, and women's health care $\left(18^{\text {th }}\right.$ ed) (Yati Afiyanti dkk, Penerjemah). Jakarta: EGC

Rini dan Nadhiroh. 2015. Hubungan Frekuensi Dan Lama Menyusu Dengan Perubahan Berat Badan Neonatus Di Wilayah Kerja Puskesmas Gandusari Kabupaten Trenggalek. Media Gizi Indonesia. Vol. 10 (1) : $38-43$

Sabrina, A. 2020. Cara Membaca KMS (Kartu Menuju Sehat), Informasi Gizi dan Tumbuh Kembang Anak. Hello Sehat. Diunggah 30 Maret 2020. https:/hellosehat.com/parenting/anak-1sampai-5-tahun/cara-membaca-kms/\#gref

Sari, Tamtomo dan Anantayu. 2017. Hubungan Teknik, Frekuensi, Durasi Menyusui dan Asupan Energi dengan Berat Badan Bayi Usia 1-6 Bulan di Puskesmas Tasikmadu Kabupaten Karanganyar. Amerta Nutr: 1-13

Soetjiningsih. 2008. ASI Petunjuk untuk Tenaga Kesehatan. Jakarta: EGC

Susanti M, dkk. 2012. Hubungan Pola Pemberian ASI dan MP-ASI dengan Gizi Buruk pada Anak 6-24 Bulan di Kelurahan Pannampu Makassar. Media Gizi Masyarakat Indonesia. Volume 1, No. 2 